\title{
Life Cycle Stages and Length of Zebrafish (Danio rerio) Exposed to DDT
}

\author{
Jules Richard Kemadjou Njiwa,* Paul Müller, and Roland Klein \\ Centre of Environmental Research, University of Saarland, D-66123 Saarbrücken Germany
}

(Received July 1, 2003; Accepted November 10, 2003)

Long-term toxicity growth tests were conducted with DDT using zebrafish (Danio rerio). The fish were exposed to concentrations of $0.05 \mu \mathrm{g} / \mathrm{l}, 0.5 \mu \mathrm{g} / \mathrm{l}, 5 \mu \mathrm{g} / \mathrm{l}$ and $50 \mu \mathrm{g} / \mathrm{l}$ DDT under flow-through conditions. The effect of the compound on the ecologically important parameters hatching rate, duration of the developmental stages and growth were the focus of interest. When exposed to $50 \mu \mathrm{g} / \mathrm{l}$ DDT, the hatching rate was 2 to 3 times lower than in embryos exposed to $0.05 \mu \mathrm{g} / \mathrm{l}$ DDT. This study demonstrates that the rearing zebrafish in the pesticide causes a reduction in body length and the durations of the life cycle stages (LCS) of the offspring are extended. These effects are increased when the fish are exposed to higher DDT concentrations.

Key words — Danio rerio, early life stage, life cycle stages, growth, $\mathrm{F}_{1}$-generation, DDT

\section{INTRODUCTION}

DDT persists for a long time in the environment. It can harm beneficial neutral species (non target) and hence significantly disturbs the ecosystem. Due to its persistence, the ecological damage of this chemical is still imminent in many parts of the world. It is nearly 40 years after the first evidence was presented that organochlorines accumulate via the food chain and at different trophic levels in the clear lake California which has been treated several times with DDT. ${ }^{1-7)}$

Fish represent important organisms for the evaluation of toxicity in the hydrosphere. One of the most important effects of the xenobiotics on fish population is the impairment of reproduction. Ecotoxicants can have an impact on reproduction at many levels, including effects on clutch size and egg quality, development of the embryos and larvae, the rate of hatching and development to sexual maturity. Tests limited to early life stages have been shown to be inadequate to investigate these parameters comprehensively. ${ }^{8)}$ A full life cycle assessment has to be carried out instead.

Although level two of the German chemical act requires a long term test that has to include reproduction, ${ }^{9)}$ no satisfactory test guidelines are avail-

\footnotetext{
*To whom correspondence should be addressed: Centre of Environmental Research, University of Saarland, D-66123 Saarbrücken Germany. Tel.: +49-179-794-6478; Fax: +49-6181304-9022; E-mail: kemadjoub@yahoo.com
}

able up to now. The zebrafish [Danio rerio (D. rerio)] is a suitable model for full life cycle assessments because zebrafish takes only 3-4 months to reach the sexual maturity. Moreover, they can be maintained in a laboratory environment at low cost and remain sexually active throughout the year.

The test employed in this study involved exposure of zebrafish to the toxin from the fertilized egg up to the mature animal. The effect on reproduction was assessed by examination of mortality, hatching rate, body length and development of the offspring. This study encompassed the examination of two generations of fish over a period of approximately 8 months. This was regarded necessary to obtain sufficient information on the duration of each life stage and the deleterious effect of the chemical on the subsequent generation. The parameters were also investigated in the offspring of exposed parents that were subsequently reared in a toxin-free environment. The second generation was assessed up to six weeks and the difference with offspring which remained exposed to DDT was determined.

\section{MATERIALS AND METHODS}

Test Species — In Europe zebrafish (D. rerio) is increasingly used in toxicological studies. The fish well known to breeders measures $3-5 \mathrm{~cm}$ in the adult state. It thrives both in soft and hard waters, grows quickly at temperatures around $26^{\circ} \mathrm{C}$ and reaches 
the sexual maturity within 3 months. Zebrafish produces gametes throughout the year, and easily reared under laboratory conditions. ${ }^{10,11)}$

Egg Collection — The fish of the $\mathrm{F}_{0}$-generation were obtained from a zoological store in Saarbrücken, Federal Republic of Germany (FRG). They were 4-5 months old at the time of arrival. Mature females were mated with males in glass aquaria. Eggs were collected in glass dishes covered with stainless steel wire mesh. The dishes were placed at the bottom of the glass aquaria. Green glass trees served as spawning substrate. Immediately after switching on the light in the morning, mating began and two hours later, glass dishes containig eggs were removed from the aquaria.

Egg Exposure — Fertilized eggs were exposed under flow-through conditions to the different concentrations of DDT ranging from $0.05 \mu \mathrm{g} / \mathrm{l}$ to $50 \mu \mathrm{g} / \mathrm{l}$ and separated by a factor of 10 . An untreated group was kept under the same conditions as control. This stage was considered to be the early life stage (ELS) of the $F_{1}$-generation of test organisms. The flowthrough system (Fig. 1) consisted of a water tank in which charcoal filtered tap water was aerated. The temperature was kept constant at $26^{\circ} \mathrm{C}\left( \pm 1^{\circ} \mathrm{C}\right)$, the $\mathrm{pH}$ value $7.9 \pm 0.2$ and $\mathrm{O}_{2}$ content $5.9( \pm 0.3) \mathrm{mg} / \mathrm{l}$. Dilution water was pumped into the glass vessels. The toxicant was added to the test solution using a micropipette and a photoperiod of $12 \mathrm{hr}$ was maintained.

Start of the Life Cycle — The life cycle experiment was started with 90 fertilized eggs per glass petridish $(8 \mathrm{~cm}$ height, $15 \mathrm{~cm}$ in diameter, $500 \mathrm{ml}$ test solution). Eggs were obtained according to the method of Nagel. ${ }^{12)}$ From day 6 young larvae were fed twice a day with AZ25 (Tetrawerke, Melle, FRG). From day 8 newly hatched brine shrimp (Artemia species) and pulverized dry food (Tetramin) were added. Two weeks later after the evaluation of the rate of hatching, the larvae were separated into 2 groups. The first group (Group I) was transferred into glass vessels $(20 \times 15 \times 30 \mathrm{~cm}, \mathrm{H} \times \mathrm{w} \times \mathrm{L}, 81$ test solution) filled with uncontaminated solution and the second group (Group II) of larvae remained exposed to DDT during their whole life time. The experiment was conducted subsequently for both cases.

Feeding with Tetramin AZ25 was gradually reduced. Excrement and surplus food were removed daily. Hatching rates, morphological abnormalities and mortality during the test were recorded.

Post-Larval Stages — After the embryonic stage, body length and survival rate were determined dur-

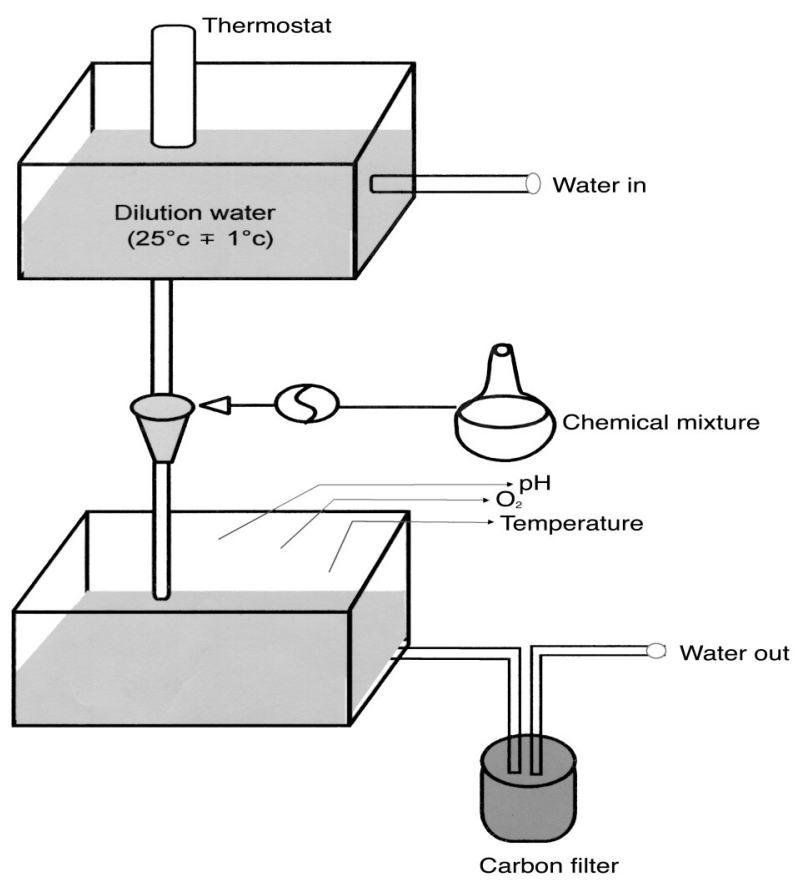

Fig. 1. Flow Through Aquarium

ing 60 days. Surviving fish were kept in larger glass aquaria $(30 \times 40 \times 25 \mathrm{~cm}, \mathrm{H} \times \mathrm{W} \times \mathrm{L}, 28$-1 test solution) until sexual maturity was reached. Water exchange was once a day. ${ }^{13,14)}$ Depending on the level of DDT in the aquaria, sexual maturity was reached after 12-17 weeks. From day 125, 10 male and 5 female fish of each test chamber were mated. The eggs laid were used for the investigation of the ELS of the $\mathrm{F}_{2}$-generation in the same way to that of the $\mathrm{F}_{1}$ generation. To assess the quality of the offspring whose parents were long term exposed to the pesticide, an evaluation of the body length was carried out during the ELS of the $\mathrm{F}_{2}$-generation.

Chemical and Chemical Analysis — DDT (CAS no. 50-29-3), CA 1,1,1-trichloro-2,2-bis ( $p$ chlorophenyl) ethane (mixed isomers)- was obtained from the company Prochem GmbH in Wesel, FRG.

DDT was extracted with ethyl acetate from water between day 65 and 125 during the washing phase of Group I fish. The samples were first filtered and the extraction was performed according to a column type CHROMABOND ${ }^{\circledR} \mathrm{C} 18 \mathrm{ec} / 6 \mathrm{ml} / 500 \mathrm{mg}$. The extracts were analyzed by the Standard Operating Procedure (SOP) for analysis of organochlorine pesticide residues in biological matrices according to the US-EPA method $608 .{ }^{15)}$ The extraction procedure was the same for each liter of all the water samples. All equipment was disinfected before use.

The mean duration of the stages was determined 
and length of fish was evaluated on fixed specimens each in triplicates. All equipment was desinfected. Comparison of body length and duration of the LCS between the tested concentrations and control was performed using the statistical $t$-test and analysis of variance (ANOVA).

\section{RESULTS}

\section{Rate of Hatching, Development to Sexual Matu- rity and Survival Rates}

Hatching did not happen, when fertilized eggs were initially exposed to $500 \mu \mathrm{g} / \mathrm{l} \mathrm{DDT}$ and the rate of hatching decreased with increasing concentrations $(5 \mu \mathrm{g} / \mathrm{l}$ and $50 \mu \mathrm{g} / \mathrm{l})$. The dose-dependant reduction of the hatching rate varied from 4 to $58 \%$ between the lowest and the highest concentration. Premature hatching occurred at $50 \mu \mathrm{g} / \mathrm{l}$ and the larvae died. At none of the tested concentrations was a $100 \%$ hatching rate recorded and it was reduced already to less than $30 \%$ at $5 \mu \mathrm{g} / \mathrm{l}$.

In Group I , from day 44 to 120 , the development was inhibited according to the concentration of DDT. However, $0.05 \mu \mathrm{g} / \mathrm{l}$ causes already a 50 $55 \%$ effect. Therefore $0.05 \mu \mathrm{g} / \mathrm{l}$ could be regarded as Low Observed Effect Concentration (LOEC). The rate of hatching of Group II fish in the $\mathrm{F}_{2}$-generation where all the fish remained exposed to DDT was lower than that were lower than that in the $\mathrm{F}_{1}$ generation (Fig. 2). In Group II, a survival rate of more than $50 \%$ was recorded only at the concentration $0.05 \mu \mathrm{g} / \mathrm{l}$ after 6 weeks of treatment. All the fish exposed to the highest tested concentration $(50 \mu \mathrm{g} / \mathrm{l})$ succumbed before day 44. Most of the fish died within the second week. In Group I, where the fish were transferred to DDT-free tanks, more than 50\% of fish survived although the survival rate was inversely correlated with the DDT concentrations (Fig. 3). Moreover, the rate of mortality decreased slightly, but remained higher in treated tanks than in controls.

\section{Length of Fish Emerged and Duration of the Life Cycle Stages}

A dose-dependant reduction of the body was recorded in Group I and Group II fish. The body length of fish was reduced by $5-25 \%$ and $1-21 \%$ in Group II and Group I, respectively (Fig. 4). A complete life cycle test starting with fertilized eggs lasted 136 days. After treatment, the life cycle experiment

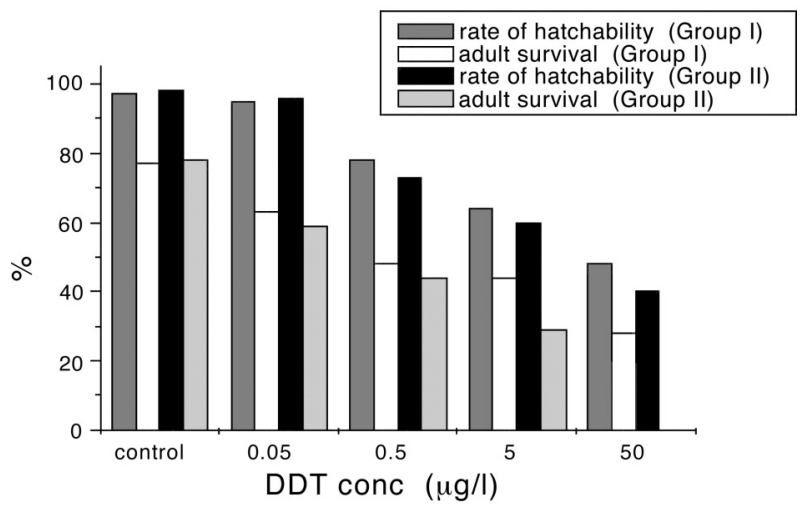

Fig. 2. Rates of Hatchability and Adult Survival of Groups I and II Fish in the $\mathrm{F}_{1}$-Generation

The absence of the adult survival at $50 \mu \mathrm{g} / \mathrm{l}$ in Group II fish is due to the death of all juvenile fish within a short time after hatching.

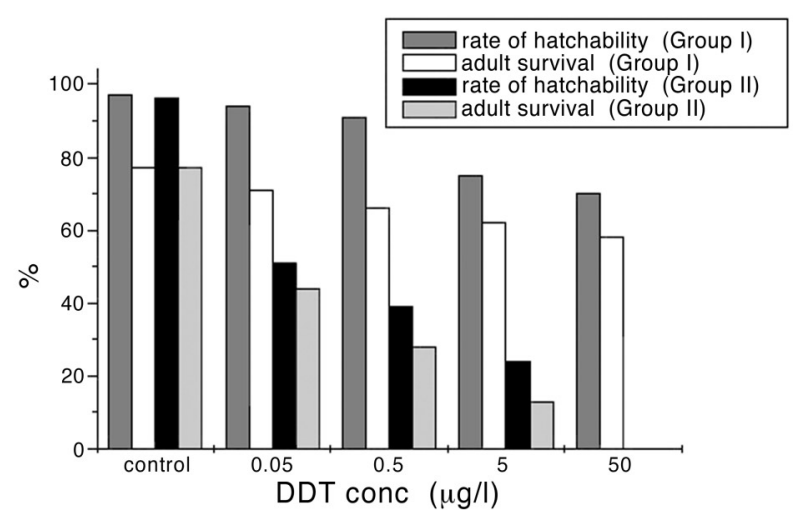

Fig. 3. Rates of Hatchability and Adult Survival of Groups I and II Fish, 6 weeks after Hatching in the $\mathrm{F}_{1}$-Generation At $50 \mu \mathrm{g} / \mathrm{l}$ no hatching occurred in Group II fish.

starting with fertilized eggs showed a dose-dependant increase of the duration of the life stages. However, a 6-33 days and a 10-38 days delay of development up to the next generation was noted in Group II and Group I, respectively (Table 1, Table 2). The delay in growth in each life stage was found to be dependant on the dose of the pesticide.

In Group I, a few days delay was also recorded during the hatching stage of eggs produced in the $\mathrm{F}_{1}$-generation and for the $\mathrm{F}_{2}$-generation. It is clear from these data that the effects of DDT were widespread up to the ELS of the $\mathrm{F}_{2}$-generation. This result was emphasized by the evaluation of body length in the $\mathrm{F}_{2}$-generation of Group I, six weeks after hatching which also demonstrated a dose-dependant reduction (Fig. 5). 


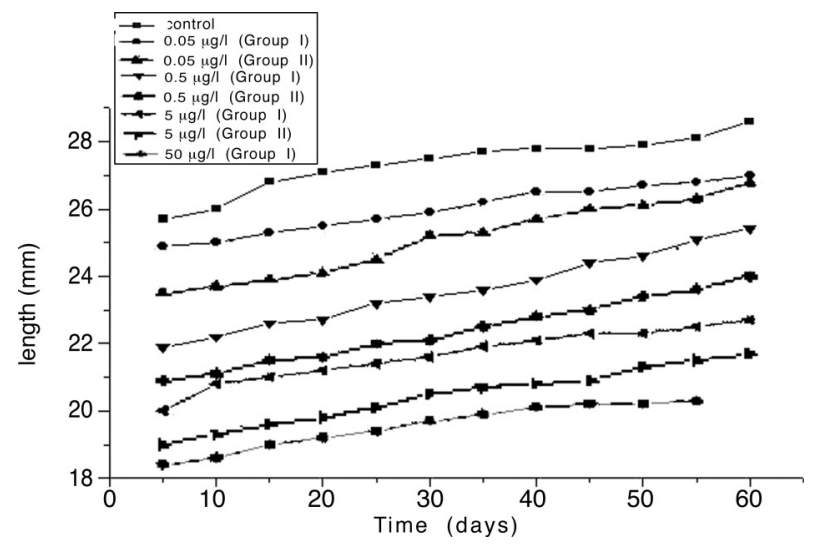

Fig. 4. Length of Groups I and II Fish Emerged within 60 days after the Larval Stage at all the DDT Tested Concentrations

For Group I: $\mathrm{N}=3$; F-ratio $=0.13$ at degree of freedom (4.40); $p<0.05$. For Group II: $\mathrm{N}=3$; F-ratio $=0.09$ at degree of freedom (3.33); $p<0.05$. At $50 \mu \mathrm{g} / \mathrm{l}$ all the fish succumbed.

Table 1. Mean Duration in Days ( \pm Standard Error) of the Life Cycle Stages up to 6 weeks in the $F_{2}$-Generation of Group I Fish

\begin{tabular}{cccccc}
\hline \hline & Control & $0.05 \mu \mathrm{g} / \mathrm{l}$ & $0.5 \mu \mathrm{g} / \mathrm{l}$ & $5 \mu \mathrm{g} / \mathrm{l}$ & $50 \mu \mathrm{g} / \mathrm{l}$ \\
& & $\mathrm{DDT}$ & $\mathrm{DDT}$ & $\mathrm{DDT}$ & $\mathrm{DDT}$ \\
\hline $\mathrm{A}$ & 0 & 0 & 0 & 0 & 0 \\
$\mathrm{~B}$ & $44 \pm 1$ & $45 \pm 1$ & $48 \pm 2$ & $52 \pm 2$ & $55 \pm 1$ \\
$\mathrm{C}$ & $87 \pm 2$ & $90 \pm 2$ & $94 \pm 3$ & $101 \pm 3$ & $\left.106 \pm 4^{a}\right)$ \\
$\mathrm{D}$ & $108 \pm 3$ & $114 \pm 4$ & $121 \pm 3$ & $131 \pm 5$ & $134 \pm 2$ \\
$\mathrm{E}$ & $175 \pm 4$ & $182 \pm 3$ & $191 \pm 5$ & $206 \pm 7$ & $212 \pm 5$ \\
\hline \multicolumn{5}{c}{ A: Start with 90 fertilized eggs. B: Development of embryos } \\
and larvae. C: Sexual maturity. D: Egg production. E: Larval stage \\
of the $\mathrm{F}_{2}$-generation. $a$ a) indicates more than 10\% mortality between \\
the larval development and sexual maturity.
\end{tabular}

\section{Quantification of DDT in Test Chambers}

The analysis of water samples in test vessels of Group I fish on day 125 demonstrated the presence of DDT residues. The higher the initial dosed concentration of the pesticide, the higher was the level of residues detected (Table 3 ).

\section{DISCUSSION}

All the tested concentrations of DDT influenced the rate of hatching, growth and duration of the LCS and therefore no No Observed Effect Concentration (NOEC) could be established.

In Group II fish, contrary to the $\mathrm{F}_{1}$-generation, $\mathrm{F}_{2}$-eggs were directly spawned into DDT treated water. That influenced the rate of hatching, which
Table 2. Duration in Days ( \pm Standard Error) of the Life Cycle Stages at the DDT Tested Concentrations up to 6 weeks in the $\mathrm{F}_{2}$-Generation of Group II Fish

\begin{tabular}{lcccc}
\hline \hline & control & $0.05 \mu \mathrm{g} / \mathrm{l}$ & $0.5 \mu \mathrm{g} / \mathrm{l}$ & $5 \mu \mathrm{g} / \mathrm{l}$ \\
& & DDT & DDT & DDT \\
\hline A & 0 & 0 & 0 & 0 \\
B & $44 \pm 1$ & $47 \pm 1^{a)}$ & $60 \pm 3^{a)}$ & $68 \pm 3^{a)}$ \\
C & $87 \pm 2$ & $97 \pm 2^{a)}$ & $111 \pm 4^{a)}$ & $128 \pm 5^{a)}$ \\
D & $108 \pm 3$ & $115 \pm 4$ & $137 \pm 5$ & $163 \pm 4$ \\
E & $175 \pm 4$ & $190 \pm 5$ & $220 \pm 7$ & $243 \pm 8$ \\
\hline
\end{tabular}

A: Start with 90 fertilized eggs. B: Development of embryos and larvae. C: Sexual maturity. D: Egg production. E: $\mathrm{F}_{2}-$ generation. a) indicates more than $10 \%$ mortality between larval stage and sexual maturity.

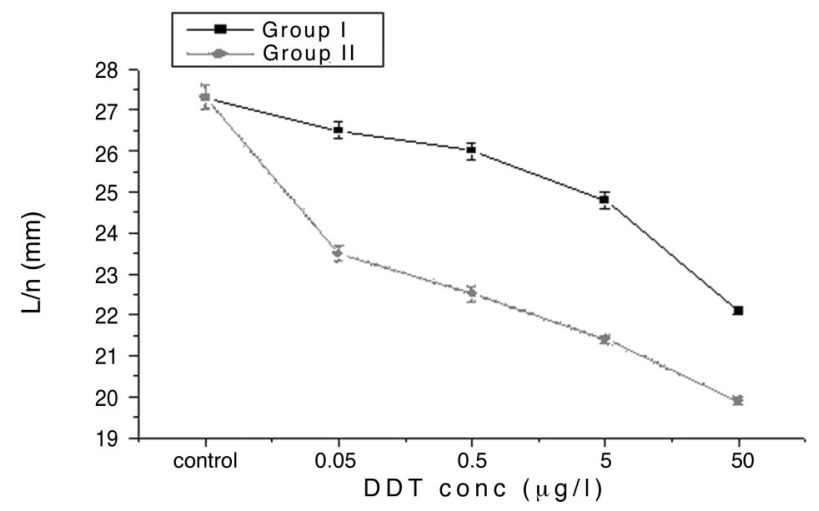

Fig. 5. Mean Length $(\mathrm{L} / \mathrm{n} \pm$ S.E.) of Juvenile Fish Taken Randomly in the ELS of the F1-Generation

Where $n=6$ is the number of fish measured at each tested concentration. S.E.: standard error.

was reduced to $10-65 \%$. Relative to controls, the reduction of the rate of hatching recorded during this study agreed with the report of Woltering ${ }^{16)}$ in 1984 in which he reviewed a total of 173 tests including exposure to metals, pesticides and xenobiotics and found that the hatching rate was reduced to $19 \%$.

But in all the cases, an increase in developmental abnormalities was not observed. In all tested concentrations and controls, all rates were less than $3 \%$. Eight larvae exposed to $50 \mu \mathrm{g} / \mathrm{l}$ DDT in Group II showed edema and died before day 14. It could be assumed that the observed deformation rate is natural agreing with data from Bresh et al. ${ }^{14)}$ who found less than 5\% deformations during an experimental time over two fish generations.

On the other hand, the growth of juvenile fish was greatly reduced at $0.5 \mu \mathrm{g} / \mathrm{l}$ and $5 \mu \mathrm{g} / \mathrm{l}$ for Group II. These reductions of the growth were not negligible. The effect of DDT on growth was evident at the higher concentrations where the fish density was 
Table 3. Evaluation of DDT Residues (ng/l) in Test Chambers of Group I Fish from Day 65 and 125 post Hatching

\begin{tabular}{clllllll}
\hline \hline Time (days) & $0.05 \mu \mathrm{g} / \mathrm{l}$ & $0.5 \mu \mathrm{g} / \mathrm{l}$ & $\mathrm{SE}$ & $5 \mu \mathrm{g} / \mathrm{l}$ & $\mathrm{SE}$ & $50 \mu \mathrm{g} / \mathrm{l}$ & $\mathrm{SE}$ \\
\hline 2 & - & 5.36 & 2.13 & 23.81 & 9.48 & 131.55 & 52.37 \\
5 & - & 5.07 & 2.01 & 24.25 & 9.65 & 134.61 & 53.57 \\
10 & - & 4.15 & 1.65 & 25.64 & 10.2 & 136.2 & 54.21 \\
15 & - & 3.2 & 1.27 & 25.76 & 10.25 & 137.21 & 54.61 \\
20 & - & 2.59 & 1.03 & 25.54 & 10.16 & 133.85 & 53.27 \\
25 & - & 2.53 & 1.01 & 23.02 & 9.16 & 125.53 & 49.96 \\
30 & - & 2.51 & 1 & 22.57 & 8.98 & 123.35 & 49.09 \\
35 & - & - & 0.83 & 22.34 & 8.89 & 120.51 & 47.96 \\
40 & - & - & & 22.11 & 8.8 & 119.26 & 47.46 \\
45 & - & - & & 21.81 & 8.68 & 119.01 & 47.36 \\
50 & - & - & & 21.76 & 8.66 & 118.93 & 47.33 \\
55 & - & - & & 21.48 & 8.55 & 118.89 & 47.31 \\
60 & - & - & & & 8.46 & 118.17 & 47.07 \\
\hline
\end{tabular}

— : indicates where residues were not detectable. S.E.: Standard Error.

lower due to the high rate of mortality. Our study suggests that the effect of DDT on the growth of zebrafish is independent from their density, which does not agree with the report of Ensenbach and Nagel. ${ }^{17)}$ However, the body length of fish was reduced by $1-24 \%$ in Group I. This reduction was higher at $50 \mu \mathrm{g} / \mathrm{l}$ suggesting a dose dependant reduction of the body length.

Although in some reports, for example Nagel ${ }^{1)}$ reported no effect on growth of zebrafish exposed to Lindane and Dichlormethane up to $150 \mu \mathrm{g} / \mathrm{l}$. We observed in our study that DDT alone at $5 \mu \mathrm{g} / \mathrm{l}$ already alters the growth of zebrafish. Moreover, the body length of fish was also reduced in Group I fish. The reduction was also dependant on the initial level of the tested chemical and was therefore higher at the highest tested concentration and up to ELS of the $\mathrm{F}_{2}$-generation. This could be explained by the detection of DDT residues in test chambers filled with untreated water in which the larvae initially exposed to DDT were transferred two weeks after hatching. In general, it could be proposed firstly that the ELS of zebrafish is very sensitive to DDT and secondly that the effects of DDT could be widespread to the offspring of the next generation. Comparing the effects of DDT on the early life stage tests of $F_{1^{-}}$ generation and that of $\mathrm{F}_{2}$-generation, it was demonstrated that raising of the parent fish in DDT influenced the quality of their offspring.

The developmental stages of the fish lasted longer in Group II animals, which remained exposed to DDT during their whole life time. The time taken was found dependant to the initial level of the pesticide. It was also the case for Group I fish although the difference in time was not that significant as in Group II. It was concluded that the effect of DDT is irreversible and the occurrence of this effect is accelerated in case of whole life time exposure which can lead to the death of the fish. In such a situation, when the fish survived, the complete life cycle lasted longer than expected. For example in Group II, at $0.5 \mu \mathrm{g} / \mathrm{l}$ the production of eggs started on day 145 whereas in the Group of untreated fish it started on day 108.

The reduced number of eggs reported during this experiment demonstrates that the reproduction and the rate of fertility of fish were disturbed by DDT.

Conduction of a life cycle test with zebrafish could be a way to get toxicological data of parameters relevant for the population. Fish were exposed for at least seven months to DDT and most of the developmental stages were recordable. In comparison to experiments with adult fish, we hope much more that toxicological data can be collected, which leads to a better assessment of the toxic potential of the chemicals.

Exposure time and DDT level were two factors which influenced the development of zebrafish. It can be concluded that timing, duration and amount of exposure are each important determinants of the outcome. There are windows of vulnerability during larval development in which exposures to DDT may have profound effects also observed in adults. Another question remains how to proceed if a test performed for the chemicals Act does not result in a NOEC value as it is the case in the present study. If this value is absolutely needed, it may be advisable to test another concentration 10-fold under the low- 
est amount applied in the former test.

A test over two generations using a suitable species, certainly is the most precise method at this time to estimate the hazard potential of a substance on representative species. Any laboratory tests, of course, yield only estimates of the effect of a substance in nature. A strong mechanistic case can be made to explain how exposure of the ELS in the $F_{1}$ generation could disturb the LCS, the population size, the growth, reproduction and life span of zebrafish up to the ELS of the $\mathrm{F}_{2}$-generation. The suggested mechanism whereby exposure to DDT could induce the quality and quantity of offsprings produced can be offered as a hypothesis on which to focus discussion and research.

Acknowledgements We thank the Centre of Environmental Research of the university of Saarland (FRG) to have availed the laboratories and funds for the fulfilment of this work.

We also thank Prof. Dr. U. Strähle for his contribution in the writing of the Manuscript.

The experiments involved in the present work comply with the current laws of the Federal Republic of Germany (FRG).

\section{REFERENCES}

1) Nagel, P. (1995) Environmental monitoring handbook for tsetse control operations, Margraf Verlag, Ministry of the Environment, Germany.

2) Crane, E. and Walker, D. E. (1983) The impact of pest management on bees and pollinaWtion, Tropical Development and Research Institute London.

3) Müller, P. (1988) Environment and Development. Effects of pesticides on Fauna and Flora, International Atomic Energy Agency Vienna. SM. 287/40, pp. 11-27.

4) National Research Council of Canada (NRCC) (1981) Environment and Development. Effects of pesticides on Fauna and Flora, International Atomic Energy Agency Vienna. SM. 287/40, pp. 11-27.

5) Peveling, R., Weyrich, J. and Müller, P. (1994) Side effects of botanicals, insect growth regulators and entmopathogenic fungi on epigeal non target arthropods on locust control. In New trends in locust control (Krall, S. and Wilps, H., Eds.), Ascot Tropical publications, Ibadan, Nigeria, pp. 321-336.

6) Weyrich, J. (1994) In situ investigations of the toxicity to identify some biosensors during exposure to Deltamethrin. In ULV applications for the control of tsetse fly in North Zimbabwe, Dissertation, Centre for Environmental Research, University of Saarland, Saarbrücken, Germany, 150pp.

7) Van der Valk, I. R. H. C. H. G. and Koeman, J. H. (1988) Ecological impact of pesticides used in developing countries. In Ministry of housing, Physical planings, Environment, The Netherlands. 120pp.

8) Donaldson, E. M. and Scherer, E. (1983) Methods to test and assess effects of chemicals on reproduction in fish. In Methods for assessing the effects of chemicals on reproductive functions (Vouk, V. B., Sheehan, P. J., eds.), Wiley and sons, Chichester, pp. 365-405.

9) Federal Environmental Agency (1990) Chemicals Act - Principles for the assessment of new chemicals under the chemicals act. Texte 28/90E, In Ministry of the Environment, Germany, pp. 45-49.

10) Caims, J., Scheier, A. and Loss, J. J. (1965) A comparison of the sensitivity to certain chemicals of adult zebra danios Brachydanio rerio (HamiltonBuchanon) and zebra danio eggs with that of adult bluegill sunfish Lepomis macrochirus. Raf. Notulae Naturale., 381, 1-9

11) Westerfield, M. (1995) The zebrafish book. Institute of neuroscience, University of Oregon, Oregon, U.S.A.

12) Nagel, R. (1986) Trials and investigation of the reproduction tests with fish. Level $2 \mathrm{ChemG}$, Federal office of the Environment, Report No. 10603043/ 01. In Ministry of the environment (Ministry of the Environment, Germany, ed.) Springer Verlag, Germany, pp. 223-230.

13) Sprage, J. B (1973) The ABC's of pollutant assay using fish. In Biol. Methods for the assessment of water quality, ASTM special technical publication, West Conshohocken, Pennsylvania, United States of America, No. 528, pp. 6-30.

14) Bresh, H., Beck, H., Ehlermann, D., Schlaszus, H. and Urbaneck, M. (1990) A long -term toxicity test comprising reproduction and growth of zebrafish with 4-chloroaniline. Arch. Environ. Contam. Toxicol., 19, 419-427

15) US-EPA (1980) Manual of analytical methods for the analysis of pesticides in human and environmental samples, United States Environmental Agency, Washington, United States of America, EPA-600/ 8-80-038, section 12c.

16) Woltering, D. M. (1984) The growth response in fish chronic and early stage toxicity tests: a critical review. Aquat. Toxicol., 5, 1-21.

17) Ensenbach, U. and Nagel, R. (1997) Toxicity of complex chemical mixtures: Acute and long-term effects on different life stages of zebrafish (Brachydanio rerio). Ecotoxicol. Environ. Saf., 30, 151-157. 